\title{
JOVENS RAPPERS NAS RUAS DO PELOURINHO, CENTRO HISTÓRICO DE SALVADOR
}

\section{YOUNG RAPPERS IN THE STREETS OF PELOURINHO, SALVADOR'S HISTORIC DISTRICT}

\section{Leila de Oliveira Pinto*}

RESUMO: O artigo apresenta os resultados e conclusões obtidos com o desenvolvimento de uma pesquisa sobre a recepção de narrativas populares em Oficinas de contos, realizadas com crianças e adolescentes em situação de rua, no Centro Histórico de Salvador. Entre outras informações relevantes, destaca-se o aparecimento inesperado do rap e de uma forma cifrada de comunicação, conhecida como "língua do pivete". A análise e interpretação desses dados configuram um conjunto de conhecimentos, psicossociais, estéticos e estilísticos, sobre o grupo estudado.

PALAVRAS-CHAVE: experiência de vida, interpretação oral, linguagem de rua, rap.

ABSTRACT: This article produces the results and conclusions obtained during research on the reception of grassroots narratives during Storytelling Workshops, carried out with street children and adolescents in Pelourinho, Salvador's historical District. Among other relevant information, the appearance of rap and a ciphered form of communication, known as street urchin's language, deserve special mention. The analysis and interpretation of these data make up psychosocial, aesthetic, and stylistic information about the group studied.

Keywords: life experience; oral interpretation; street language; rap.

\footnotetext{
* Psicóloga, Psicanalista, Doutora em Letras e Linguística (UFBA), Professora Assistente da Escola Bahiana de Medicina e Saúde Pública EBMSP - Salvador-BA. leilapsi@uol.com.br
} 



\section{INTRODUÇÃO}

Uma parte do trabalho de campo para o desenvolvimento de minha Tese de doutorado foi realizada no Pelourinho, Centro Histórico de Salvador, com crianças e adolescentes em situação de rua que apresentavam laços enfraquecidos ou mesmo rompidos com suas famílias. Como hipótese de trabalho, considerei a possibilidade de delimitar conhecimentos, de natureza psicossocial, a respeito de indivíduos que têm sido tomados como objeto de exclusão social. O principal objetivo desta pesquisa consistiu em avaliar a produção de texto oral da população-alvo, por meio da realização de Oficinas de contos da tradição popular. Com este intuito, entre setembro de 2006 e agosto de 2007, as Oficinas reuniram, semanalmente, grupos constituídos por cinco participantes, do sexo masculino, entre nove e 16 anos. ${ }^{1}$

Essas Oficinas contaram com a presença de 38 crianças e adolescentes, de ambos os sexos, que escolheram os contos a partir do interesse provocado pelo tamanho dos livros e colorido das gravuras, desde que a maioria

\footnotetext{
${ }^{1}$ Entre maio e agosto de 2007, o trabalho de campo foi estendido para as Casas de Acolhimento da Fundação Cidade Mãe, Prefeitura de Salvador. Adiante, em fevereiro de 2009, a Tese foi defendida no Instituto de Letras, Universidade Federal da Bahia - UFBA, sob orientação da $\operatorname{Prof}^{\mathrm{a}} \mathrm{Dr}^{\mathrm{a}}$ Eneida Leal Cunha.
} 
não era alfabetizada. Logo após a contação de histórias, os ouvintes eram convidados a narrar "sua" história, o que levou uma menina e 15 meninos a optarem espontaneamente pelo rap, abreviatura para rhythm and poetry, estilo musical caracterizado pela recitação de narrativas ritmadas. Essa distribuição corresponde a $42 \%$ do total, o que sugere que o estilo de vida nas ruas acarreta dificuldades para estruturar uma narrativa de modo convencional. Em contrapartida, o rap forneceu uma oportunidade para que esses sujeitos pudessem falar de si, pois as canções escolhidas têm como tema os problemas enfrentados pelos grupos marginalizados, em conformidade com as histórias de vida narradas pelos participantes.

Antes de prosseguir, gostaria de salientar a natureza qualitativa deste estudo, que toma os números como índices de respostas, com o objetivo de facilitar a análise e interpretação dos resultados. Também é digno de nota que todos os meninos que se encontravam no Centro Histórico de Salvador faziam uso abusivo de crack. Trata-se de uma droga de teor ofensivo cujo consumo intenso pode provocar a degradação biopsicossocial dos usuários. Entre os comportamentos de risco, destaco a participação em roubos e assaltos, o envolvimento com o tráfico de drogas, abuso e exploração sexual. Portanto, a população-alvo estava exposta a danos, físicos, morais, psicológicos, de difícil enfrentamento até mesmo para adultos.

As Oficinas foram realizadas na Praça do Terreiro de Jesus, local que abriga um conjunto arquitetônico formado por casarões, igrejas e monumentos, que datam do século XVII. Reconhecido como patrimônio cultural da humanidade pela UNESCO - Organização das Nações Unidas para a educação, ciência e cultura - e uma das principais atrações turísticas da cidade, o Centro Histórico de Salvador é, lamentavelmente, um lugar que apresenta graves problemas sociais, a exemplo da concentração de moradores de rua, entre os quais assinalo a presença dos mais jovens. Além do espaço público, contei com o apoio do Axé-Buzu, um ônibus que integra o Programa de Educação de Rua do Projeto Axé, sociedade civil sem fins lucrativos cujo principal objetivo consiste na defesa dos direitos de crianças e adolescentes economicamente carentes. Adaptado com mesas, cadeiras, aparelhos de TV, vídeo e som, estantes com livros, jogos, material para desenho e instrumentos musicais, o Buzu tem como principal objetivo acolher aqueles que estão em situação de rua.

Considero que o aparecimento inesperado das narrativas cantadas configura um dado significativo e, por isso, decidi empreender uma análise no intuito de avaliar a função do rap para crianças e adolescentes 
em situação de rua. Não se trata de uma preferência exclusiva, pois alguns participantes escolheram outros tipos de música, como a axé-music, que ocupa o segundo lugar entre os ritmos selecionados. Por isso, descarto antecipadamente qualquer tentativa de estabelecer correlações estritas entre o comportamento desses meninos e o rap.

Neste sentido, Sansone (1997) critica a abordagem tradicional da etnomusicologia que associa determinados estilos musicais com grupos específicos. Daí resulta a delimitação de identidades e comportamentos estáticos, construídos a partir da preferência musical. O autor argumenta que essas conclusões não podem ser generalizadas, pois ele não encontrou associação direta entre gênero musical, etnicidade e grupo, nos resultados obtidos com uma pesquisa sobre of funk baiano e carioca. Essas considerações sugerem cautela na interpretação dos dados que registram o aparecimento significativo do rap entre aqueles que participaram das Oficinas de contos. $\mathrm{Na}$ tentativa de alcançar conclusões consistentes, considero fundamental contextualizar o aparecimento do rap.

\section{MOVIMENTO HIP-HOP}

Segundo Chang (2007), o rap surgiu nos guetos de Nova Iorque, ligado ao movimento hip-hop. Nos anos 70, as precárias condições de vida das classes populares, que enfrentavam dificuldades relativas à moradia, emprego, segurança, transporte, discriminação racial e de gênero, adquiriram proporções agudas no South Bronx, cenário de brigas de gangues, tráfico de drogas e concentração de usuários. Sob a responsabilidade de afro-americanos, caribenhos e hispânicos, os descontentamentos sociais impulsionaram formas de expressão que articulavam um discurso político com a prática da vida, tendo a arte como mediadora. Desse modo, à luz da dinâmica cultural da contemporaneidade, as manifestações musicais, plásticas e cênicas, configuradas respectivamente no $\mathrm{rap}^{2}$, grafite e break, reinterpretaram a problemática urbana que afetava as áreas mais pobres da cidade.

De acordo com Rose (1997), o hip-hop representa um recurso identitário alternativo para jovens suburbanos que assim encontram meios para simultaneamente denunciar e contestar questões sociais, enquanto se divertem. Desse modo, torna-se possível reivindicar o reconhecimento de

\footnotetext{
${ }^{2}$ Além dos cantores e músicos, o rap conta com a participação de disc-jóqueis ou DJ’s, que utilizam toca-discos como instrumento musical.
} 
igualdades e o respeito pelas diferenças, em alinhamento com a tendência pós-moderna de defesa das singularidades dos sujeitos e grupos. Outros autores consideram o rap como o moderno sucessor das tradições orais dos negros, que dele se utilizam para articular "elementos do discurso, da música, da dança, da exibição para, por meio das performances, dar vida a novas identidades e posições do sujeito" (ROSE, 1997: 194).

Sem perder de vista a vinculação com a cultura negra, Rose conclui que essas considerações marginalizam a importância do rap como música e desconsideram o contexto pós-industrial de onde emergiu. A autora argumenta que o rap não apareceu isoladamente como uma forma da poética oral, mas como elemento de um movimento mais amplo, associado à dinâmica observada nos grandes centros urbanos, no final do século XX. O desenvolvimento dos meios de comunicação de massa, evolução das tecnologias e do mercado financeiro, globalização da economia e imigração maciça das populações de países do Terceiro mundo determinaram modificações que permitiram a transformação dos "produtos tecnológicos, que se acumularam como lixo na cultura e na indústria, em fontes de prazer e de poder" (ROSE, 1997: 192).

As manifestações para um público crescente permitiram a troca de experiências, bem como aguçaram a capacidade de reflexão crítica, expressa nas letras de canções que mimetizam um cotidiano permeado por brigas, assassinatos, relação com o narcotráfico e abuso policial. Através das canções, a violência é ritualizada e simbolizada nos "combates" dos rappers que assim procuram substituir a violência real pelo simbolismo das palavras. Embora esta substituição nem sempre seja alcançada, as ressonâncias culturais do movimento favoreceram sua popularização entre jovens marginalizados e graças à tecnologia das comunicações de massa, em pouco tempo, o movimento hip-hop divulgou-se para comunidades periféricas de outras cidades e continentes.

No Brasil, até o final dos anos 80, o interesse pelo rap encontrava-se limitado à juventude periférica dos grandes centros urbanos. A partir da década de 90 , as narrativas cantadas têm conquistado outros segmentos sociais e atualmente alcançaram o status de cultura popular urbana. Quando comparado com outras formas de expressão do hip-hop, mais exatamente com o break e o grafite, o rap nacional ocupa posição hegemônica e sua popularização está relacionada com a valorização dos ritmos da cultura negra. Embora não mantenha vinculações formais com o movimento negro, este estilo musical compartilha preocupações com a conscientização 
e "atitude" - palavra de ordem que designa a linha de conduta assumida pelos adeptos - frente às questões raciais e sociais.

De maneira similar ao que ocorreu em Nova Iorque, a produção nacional expressa conflitos, preconceitos e segregações que afetam o cotidiano das comunidades periféricas. Desse modo, as diferenças, tensões sociais e singularidades dos moradores de favelas e subúrbios conquistam visibilidade no espaço urbano. Segundo Herschmann (1997), a diversidade territorial corre em paralelo com a tendência à homogeneização, típica das culturas de massa, expressa através da apropriação e adaptação da cultura do outro. O autor observa que este processo resulta na "estética da versão", cuja flexibilidade assegura a inserção no mercado de grupos vítimas de exclusão social. O hibridismo musical é intensificado pelo processo de recepção em diferentes lugares, o que determina o aparecimento de expressões locais. E desde que se trata de uma modalidade da cultura de massa, os grupos que se apropriam do capital cultural alheio também são consumidos por outros grupos e segmentos sociais.

Para Rose, o hibridismo musical não chega a afetar a estrutura do rap, composta por três pontos, ou seja, fluxo, rupturas sucessivas e estratificação. As canções são organizadas como narrativas que apresentam um fluxo contínuo, marcado por rupturas que realçam a quebra da fluência do ritmo básico. Esse processo de construção pode ser observado na constante tensão e negociação com a cultura hegemônica, o que levou a autora a considerar o hip-hop como "um estilo que ninguém segura" (ROSE, 1997: 192). Por isso, apesar das tentativas, a indústria cultural ainda não conseguiu exercer o pretendido controle sobre o rap, cujas letras e mensagens provocativas sobrepõem-se ao ritmo musical.

As semelhanças sonoras das canções são intensificadas pelo emprego da mesma base, ou fundo musical, em diferentes composições. Em contrapartida, existem diversas vertentes, caracterizadas por orientações socioculturais variadas, o que pode ser observado no conteúdo temático das letras das músicas. O "rap positivo", por exemplo, privilegia valores como solidariedade, verdade, cumplicidade e responsabilidade; critica o uso de drogas e prega o fim da violência. Os mais radicais chegam a assumir uma postura que condena o sexo livre e qualquer tipo de vício. Já o "gangsta rap", conhecido nas favelas brasileiras como "rap do contexto", apresenta letras que fazem apologia do crime e ridicularizam a polícia, enquanto os "raps da galera" exaltam bandidos, em versões de músicas conhecidas com letras modificadas. A referência às armas sinaliza a banalização da violência, 
acentuada pelo uso de tradicionais cantigas de roda como fundo musical (ABRAMOVAY et al., 1999).

A ênfase nos conflitos afeta o imaginário social urbano que, usualmente, associa o rap com o crime e a violência. Em consonância com o senso comum, os estudos de cunho ortodoxo propõem interpretações de desvio e transgressão social. Além do conteúdo das letras e atitude provocativa, alguns rappers são acusados de manterem ligação com organizações criminosas, especialmente com o narcotráfico. Por outro lado, a postura politizada de alguns grupos fornece subsídios para acusações de intolerância e incitação ao racismo.

O cenário intelectual contemporâneo encontra nesses fenômenos oportunidade para o desenvolvimento de estudos e pesquisas cujos resultados afetam as tradicionais avaliações de natureza moralizante. Entre outras considerações, gostaria de chamar a atenção para as investigações que assinalam a importância do rap como elemento articulador entre uma forma específica de poética musical com propostas de contestação e transformação social. Daí resulta a construção de identidades que configuram um novo estilo de vida, caracterizado pela assunção das diferenças. Como consequência, os "espaços de vida não são mais ocultados com vergonha, como o fizeram muitas das antigas gerações de moradores de favelas e periferias, mas assumidos explicitamente em seus poemas e 'gritos de guerra' rituais' (FAUSTO NETO; QUIROGA, 2000: 232).

Outros autores, como Arce (1997), consideram que a captação pelos mercados de consumo resulta na popularização do rap mais como modismo do que como movimento cultural. $\mathrm{O}$ autor lembra que alguns grupos e cantores submetem-se aos ditames da indústria fonográfica com o objetivo de facilitar a comercialização, o que interfere nos significados dos seus trabalhos. Apesar disso, o autor não perde de vista que isto ocorre em paralelo com a constituição e manutenção de espaços que agregam jovens que lutam por seus direitos.

Além de cumprir os objetivos de denunciar, contestar e exigir transformações sociais, alguns jovens dele se utilizam como atividade de lazer, bem como o empregam como recurso metodológico para organizar movimentos sociais e trabalhos comunitários, desenvolvidos em oficinas, palestras e campanhas beneficentes. Segundo Carvalho (2000), a participação nesses grupos favorece a construção de identidades orientadas por compromissos de cunho sociopolítico com a comunidade. 
Portanto, trata-se de uma expressão juvenil por excelência, pontuada por características híbridas, típicas da cultura de massa, o que pode ser observado no aparecimento conjugado de reivindicações de direitos de cidadania com temas marginais, relatos de conflitos que se alternam com propostas de negociação, atitude contestadora com submissão às regras ditadas pela indústria cultural. Assim, em detrimento da associação do rap com a violência urbana, o estilo híbrido tem favorecido o aumento crescente do número de fãs, de classes sociais diferenciadas, o que indica que a posição periférica pode ocupar um lugar central na cultura contemporânea.

\section{RAP NAS OFICINAS DE CONTOS}

Entre os raps selecionados pelos participantes das Oficinas de contos foi possível identificar a autoria de sete canções: cinco do grupo Racionais MC; uma do grupo Facção Central e uma do rapper MV Bill. Com exceção desta canção, cantada na terceira pessoa do singular, as demais são narradas na primeira pessoa, o que favoreceu a identificação dos participantes das Oficinas de contos com os personagens das canções. Por outro lado, não foi possível identificar a autoria de outros raps e, entre esses, pelo menos três foram considerados como tendo sido compostos por "meninos de rua". Após o canto, no intuito de favorecer a reflexão e a associação livre em torno dos temas levantados, procurei abordar questões singulares e dificuldades comuns ao grupo.

Para fins desta exposição, apresento em seguida alguns desdobramentos obtidos a partir do aparecimento do rap nas Oficinas de contos. Com o objetivo de preservar a identidade dos participantes, todos os nomes foram substituídos, enquanto os relatos e as canções foram transcritos tal como foram enunciados, mesmo nos casos que infringem o padrão proposto pela norma culta e independente das variações com relação às composições originais gravadas pelos rappers. Para Ticiano, 16 anos, a postura retraída assumida inicialmente cedeu frente à visão do gravador que favoreceu o aparecimento de três raps. Entre os escolhidos, "Eu sou 157"3 lhe permitiu falar sobre os furtos que ele próprio cometia. A letra deste rap expressa os sentimentos de exaltação e desconfiança de um ladrão, tomado como herói pelos "meninos de rua" nos versos da canção:

\footnotetext{
${ }^{3}$ Segundo informações prestadas pelos próprios meninos, o artigo 157 do Código Penal brasileiro prevê a punição para aqueles que cometem assalto à mão armada.
} 
Hoje eu sou ladrão/ artigo 157/ as cachorra me ama/ os playboy se derrete/ hoje eu sou ladrão/ artigo 157/ a polícia bola um plano/ sou herói dos pivete/ uma pá de branco cresce os zoio quando eu chego/Zé povinho é foda/ ô, é não, nego/ eu to de mal com o mundo/ terça-feira à tarde/ já fumei um ligeiro com os covarde/ eu só confio em mim/mais ninguém/ você me entende/ fala gíria bem/ até papagaio aprende/ vagabundo assalta banco usando [incompreensível]/ civil dá o bote usando caminhão da light/ presente de grego é cavalo de Troia/ nem tudo que brilha é relíquia nem joia/ lembra aquela fita lá/ ô, fala aí Jão/ o branco veio aí/ mó cara de ladrão/ hey, como é que é rapa?/ calor do caraio/ cê sabe/ licença aqui/ xô fumá/ passa a bola, Romário/ meio desconfiante/ é, nem percebi/ diz que tem um camarada que vende isso e aquilo/ quem é?/ quero um quilo/ um quilo de que Jão?/ cê conhece quem?/ sei lá/ sei não/ hein?/ eu sou novo também/ irmão, quando ele falô/ o quilo é o terço/ o terço é o milho/ a ficha caiu/ onde é que já se viu/ tá de piolhagem/ virge, meu irmão/ o negão era polícia/ virge, irmão Castelo/ hoje eu sou ladrão/ artigo 157/ as cachorra me ama/ os playboy se derrete (Ticiano).

Embora se trate de um rap longo, Ticiano cantou sem interrupções e com poucas alterações, quando comparamos seu canto com a letra desta canção gravada pelo grupo Racionais MC. De fato, este rap suscitou o aparecimento de associações que permitiram ao adolescente abordar pontos relacionados com sua história de vida. Após cantar, ele relatou que costumava roubar para comprar roupas, tênis e acessórios que refletiam o visual habitualmente adotado pelos rappers. Ele também falou sobre sua intenção de parar de roubar, assumida desde que começou a fumar crack. Frente às dificuldades para cumprir esta proposta, ele estabeleceu limites contra o uso abusivo, na medida em que não empregava o dinheiro roubado na compra da droga. Desse modo, Ticiano delimita uma estratégia para reduzir o consumo, plasmada na desconexão entre os furtos realizados e a aquisição de crack, por intermédio de um pacto de linguagem assumido pelo sujeito: "Nesse tempo, eu fumava maconha, e depois que comecei a usar crack eu parei de roubar porque eu sabia que eu ia roubar pra fumar crack. E não adiantou nada que até hoje eu roubo. Eu só não vou roubar pra fumar crack."

Os furtos foram justificados através de reflexões críticas a respeito da atitude da sociedade e do governo que "não procura saber por que você tá robano". Portanto, o rap operou como um instrumento para formar o laço social e abordar as questões do sujeito, pois de início, Ticiano recusou o convite para participar da Oficina de contos. Após cantar, ele falou sobre o envolvimento de sua mãe com o uso de cocaína e o tráfico de crack, bem como sobre os problemas que ele encontrou ao buscar tratamento para 
livrar-se da droga: "Se fosse assim de chegar agora, agora, agora, eu ia. Mas pra marcar dia não consegue que eu marquei com a tia e ficou... Tive de esperar sete dia. Eu esperei cinco, não consegui esperar os outro dois, fui pra rua fumar. Fumei, não tive mais vontade de ir."

As reflexões de Ticiano atestam que ele tinha conhecimento não apenas das dificuldades para livrar-se do crack, como também do potencial ofensivo desta droga: "Crack? Ele é tá se matando sozinho. Não é chegar e falar: - Vou parar de usar essa droga agora. Eu não uso mais essa droga hoje. Né assim e chegar e falar não. Quem não usa, pra falar é fácil. Agora, quem usa, pra falar que é difícil." Neste ponto, ele afirmou que queria ir para uma "casa de recuperação" sem precisar recorrer à ajuda da sua família. De maneira similar, quase todos os participantes referiram-se, ao longo das Oficinas de contos, à intenção de procurar tratamento para interromper o uso de crack.

Entretanto, depois de avaliar as opções disponíveis, fui obrigada a concluir que, em Salvador, não existiam serviços de saúde especializados no tratamento do consumo de drogas na infância e adolescência. Isso me fez ficar mais atenta, no sentido de otimizar os objetivos pretendidos por este estudo. O fato é que a preferência pelo rap apareceu associada com o tema das drogas, o que pode ser lido na letra desta canção: "SOS, SOS/ deu um pau/ ficou no estresse/ na brita/ vira na brita/ deu um pau/virou a menina/ essa mina deu um pau/ virou no estresse". Após cantar, Ticiano explicou: "Um viciado que fez essa música. Então, quer dizer que se você der um pau nela [pedra, crack], cê quer fumar mais. Então, quanto mais você fuma a sensação, cê quer mais! A onda só é essa, cê fuma uma, cê quer mais! Nunca para, nunca para." Assim configuram-se questões a respeito dos dispositivos para enfrentar a "fissura", isto é, a vontade avassaladora de usar a droga, com o auxílio do rap.

Nas letras das canções, os meninos encontram referências para diluir as fronteiras entre legalidade e ilegalidade, o que contribui para a adoção de códigos heterodoxos. A adesão é corroborada pela inadequação dos serviços públicos à realidade dos "meninos de rua", no que pese as ações promovidas por algumas instituições, governamentais e não governamentais, na cidade de Salvador. $\mathrm{O}$ fato é que as contingências que afetam as vidas dessas crianças dificultam o acesso à saúde, educação, segurança e justiça. Essas circunstâncias são agravadas pelo afastamento familiar, o que favorece a vinculação com o submundo do crime, cujas "autoridades" preenchem as lacunas existentes. Sobretudo quando se trata do "gangsta rap", não se pode perder de vista o risco de envolvimento com atividades ilícitas. 
Ao apropriar-se das letras das canções, cada sujeito imprime novos sentidos, o que é facilitado pela linguagem que o rap partilha com a "língua da rua". De maneira similar às narrativas da tradição popular, as narrativas ritmadas configuram um recurso para transmitir conselhos, refletir sobre circunstâncias da vida e enunciar desejos. Por um lado, trata-se do desejo do compositor, pois frente à dificuldade para compor uma canção, os meninos apropriam-se das letras compostas por terceiros. No entanto, a seletividade do texto, acionada pelo processo de recepção, circunscreve algo que diz respeito ao próprio sujeito.

Desse modo, a cultura oferece uma oportunidade para o sujeito reinventar-se. Trata-se daquilo que cada um faz com o rap, e não o que este faz pelo sujeito, desde que a cultura implica necessariamente um processo contínuo de vir a ser. Com isso, alguma diferenciação pode aparecer e graças à singularidade da recepção em nenhum caso a canção foi simplesmente repetida. Neste sentido, um dos raps mais cantados nas Oficinas de contos, "Minha mão pequena", do grupo Facção Central, recebeu diferentes significados a depender daquele que cantava. ${ }^{4}$ Neste caso, a identificação com o personagem da canção é facilmente alcançada, pois a temática gira em torno da difícil trajetória de um menino, expressa nos versos deste rap:

Minha mão pequena/ bate no vrido do carro/ no braço se destaca/ queimadura de cigarro/ a chuva forte/ ensopa a camisa e o short/ qualquer dia a pneumonia/ me faz tossir até a morte/ uma moeda, um passe/ me livra do inferno/ não me faz chegá em casa/ inda apanhá de fio de ferro/ meu playground não tem balança, escorregador/só mãe vadia perguntando quanto você ganhou/ jogando na cara que tentou te abortar/ que tomou umas cinco injeção pra te tirar/ quando eu era nenê/ tentou me vender uma pá de vez/ quase eu fui criado/ por um rapaz inglês/ olho roxo, coração/ porra, que foi que eu fiz?/ pra em vez de tá brincando/ tá colecionando cicatriz/ por que não pensou antes de abrir as perna?/ filho não nasce pra sofrer/ não pede pra vir pra Terra pra sofrer/ seu papel devia ser/ cuidar de mim, cuidar de mim/ não brigar/ não me espancar, torturar/ nunca me bater/ eu não pedi pra nascer/minha goma é suja/ louça sem lavar/ seringa usada/ camisinha em todo lugar/ cabelo despenteado/ bafo de aguardente/ é raro quando ela escova os dente/ várias armas dos outro muquiadas no teto/ na pia, barata disputa os resto/ queria te matar, mas não sou igual a você/ prefiro morrer (Manuel).

\footnotetext{
${ }^{4}$ Este rap foi cantado por Jack, Manuel, Miguel, Roni, Saulo e Willie.
} 
A letra deste rap, cantado em diversas Oficinas, serviu como prelúdio para que cada participante pudesse falar do relacionamento com sua mãe. Contudo, em detrimento do abandono e da violência familiar, nenhum participante identificou sua mãe com a representação negativa da canção. Antes procuraram justificar o afastamento materno por morte, dificuldades financeiras ou mesmo pela impotência para enfrentar a agressividade do pai. Este, quase sempre, é representado de modo desqualificado, como bêbado, marginal ou usuário de drogas.

Depois de cantar, Jack, 16 anos, em situação de rua há mais de quatro anos, chorou e após hesitar falou sobre a morte de sua mãe, ocorrida diante de seus olhos, quando ele estava com seis anos. Depois disso, os conflitos constantes com seu pai, traficante de drogas, culminaram num ato de extrema violência, seguido de retaliação. Aos 11 anos, depois de ter sido esfaqueado por seu pai, Jack tentou furá-lo com um garfo. Acusado de tentativa de homicídio pela madrasta, o adolescente foi preso numa instituição especializada durante um ano e cinco meses. Reconquistada a liberdade, ele não retornou para sua casa. Fixou-se no Centro Histórico de Salvador, onde encontrou um companheiro chamado Saulo. Em dupla, eles escolheram e cantaram um trecho do rap "Marquinho Cabeção" de MV Bill:

Cê precisa conhecer/ a história de Marquinho Cabeção/ 15 anos de idade/ revoltado então/ barraco de madeira/ no meio da favela/ sua mãe ajoelhada/ acendia uma vela/ rezava/ pedindo para Oxalá/ que ajudasse o Marquinho/ a se levantar/ mas o seu sonho era ser jogador de futebol/ ficava sentado debaixo do sol (Jack e Saulo).

Mas qual era o sonho desses meninos? Jack chegou a esboçar o desejo de tornar-se educador do Axé para "tirar as criança da rua, botar na atividade, levar pra casa. Ruim tá nesse mundo de crime, de ladrão". Cansado de conseguir dinheiro e crack com facilidade, Saulo procurou tratamento na Casa de Acolhimento Dom Timóteo, Prefeitura de Salvador. Como não encontrou, o adolescente roubou o celular de um educador, que trocou por pedras de crack ao retornar para o Pelourinho. Portanto, para esses adolescentes, a droga aparece como um recurso para enfrentar uma realidade dura, marcada pela impossibilidade de voltar para casa, violência nas ruas, inexistência de centros especializados no tratamento do consumo de drogas na infância e adolescência e de instituições adaptadas às suas demandas, preocupações e interesses. 
Por outro lado, não foi possível identificar uma autoria para o rap $p^{5}$ mais popular entre os participantes deste estudo. Segundo informações prestadas pelos jovens cantores, este rap foi composto coletivamente por "meninos de rua". O conteúdo temático associa o uso de drogas com assaltos e risco de morte, mescla conselhos morais com um apelo de cunho religioso, como também oferece a oportunidade de o sujeito inserir-se e dar continuidade à narrativa:

Tava sentado/ na porta da escola/ de repente deu um vício/ de fumar e cheirar cola/ a droga preferida do Brasil é a maconha/ se você não trabalhar/ seu pensamento é roubar/ no primeiro assalto/ você leva sorte/ escapa da polícia/ e também da morte/ no segundo assalto/ seu destino é cancelado/ pela polícia acaba sendo baleado/ com uma bala na cabeça/ outra no coração/ é mais um fim de um ladrão/ mas o remédio do vício/ está dentro de você/ tenha fé em Deus/ e a coragem de viver/ mais uma coisa/ queu preciso lhe falar/ um menino de rua que não tem onde morar/ sua rua é sua cama/ sua rua são o chão/ resto de comida pra alimentação (Jack, Saulo e Willie).

Portanto, os meninos utilizam os eventos que configuram sua história de vida, ao invés de recorrer às fantasias e devaneios que, segundo Freud (1908), constituem as fontes de onde os escritores criativos retiram material para a produção literária. Aqui se descortina uma interrogação a respeito da capacidade imaginativa dos participantes deste estudo. De uma parte, podemos concluir que o aparecimento inesperado do rap sinaliza uma demanda desses sujeitos para falar de si. De outra parte, é fato que esses sujeitos precisam investir seu potencial criativo, de maneira maciça, nas questões de sua sobrevivência, pois eles "precisam se reinventar permanentemente para manter retesado o arco da surpresa, que é sinônimo de eficácia" (SILVA, 1996: 29).

Daí a importância da constituição de espaços socioculturais, a exemplo das Oficinas de contos, desde que a elaboração literária permite transformar o sofrimento provocado por uma realidade adversa em motivo de prazer (FREUD, 1908). Isto pode ser alcançado graças à representação do vivido sob o ordenamento simbólico das leis da linguagem. Neste sentido, o rap contribuiu para a construção do laço social e expressividade, sobretudo daqueles que apresentavam dificuldades para narrar "sua" história de forma

\footnotetext{
${ }^{5}$ Este rap foi cantado por Jack, Manuel, Mário, Miguel, Roni, Saulo, Walter e Willie.
} 
convencional. Esta possibilidade estrutura-se a partir da identificação ao rap, que suscita questões sobre os mecanismos aí operantes.

\section{IDENTIDADES OU IDENTIFICAÇÕES?}

Os estudiosos e pesquisadores consultados são unânimes em afirmar que o rap favorece a formação de identidades para sujeitos cuja representação coletiva tem como marca o desamparo e o acesso limitado às vias tradicionais para obtenção de status social. A postura crítica e a ênfase na resistência cultural oferecem elementos simbólicos, expressos através da linguagem, música, roupas e danças, para a construção identitária de sujeitos e grupos marginalizados. Esta ocorre sob a orientação de traços estéticos e estilísticos que asseguram sentimentos de reconhecimento, vínculos de solidariedade e pertencimento grupal. Trata-se da formação de identidades culturais, no sentido da assunção coletiva de determinados traços.

O tema é complexo e, por isso, destaco apenas as formulações que podem contribuir para avaliar a qualidade da identificação ao rap para meninos em situação de rua. No plano imaginário, a identidade designa a constância e continuidade de uma existência estável, inseparável de um corpo, que comporta o reconhecimento de si e dos demais. Enquanto a identificação corresponde à "mais remota expressão de um laço emocional com outra pessoa" (FREUD, 1921: 133). Em seu estudo sobre a psicologia das massas, Freud (1921) observa que a identificação ocorre a partir de três fontes, mas em qualquer caso, ela é parcial e limitada em grau máximo, pois o sujeito toma emprestado um único traço daquele com quem se identifica.

Para fins deste estudo, vou centrar a discussão na identificação primária. Trata-se da identificação a um traço tomado do pai, para ser como ele, segundo o mecanismo psicológico da incorporação. Esta opera "como um derivado da primeira fase da organização da libido, da fase oral, em que o objeto que prezamos e pelo qual ansiamos é assimilado pela ingestão, sendo dessa maneira aniquilado como tal" (FREUD, 1921: 133-134). Este tipo de identificação implica necessariamente a constituição de um laço com o pai, o que serve como fundamento para todos os laços que se seguirão. Portanto, não se trata de tomar o pai como objeto para tê--lo, pois a primeira identificação é anterior à escolha objetal.

A identificação por incorporação é delineada a partir de um argumento mítico, descrito por Freud em "Totem e tabu”, em sua busca de respostas para a "primitiva história da família humana" (FREUD, 1921: 139). Ele observa que o sentimento de fraternidade surge quando os membros do clã 
totêmico ${ }^{6}$ unem-se para matar o pai, cuja liderança caracterizava-se pela crueldade e despotismo. Após o assassinato, os irmãos devoram pedaços do corpo do pai morto e assim realizam "a identificação com ele, cada um deles adquirindo uma parte de sua força" (FREUD, 1913: 170). Contudo, em detrimento da ação coletiva, cada um adquire atributos singulares a depender da parte do corpo que foi devorada.

Desse modo, Freud delineia o mito da constituição singular de cada sujeito, desde que apenas o pai morto pode ser alçado ao estatuto do pai simbólico. Assim se configura a função do Nome do Pai que, segundo Lacan (1999), assegura a possibilidade de dar nome às coisas. "Nomear aqui não é nomear uma coleção, um conjunto de atributos. Colocada a equivalência entre Nome do Pai e sua função radical, será nome em sua essência de ser ausente: ser enquanto que nomeia" (CRUGLAK, 2001: 57-58).

$\mathrm{E}$ aqui eu me arrisco a comparar o banquete totêmico com o ritual do crack, facilmente observável na Rua 28 de Setembro, no Pelourinho, onde crianças e adolescentes compram e consomem drogas livremente. Com o conhecimento e a conivência da comunidade, da polícia e da sociedade, pois o fato tem sido exaustivamente divulgado pela imprensa. Mas se os deixam fumar, por que eles fumam? E eu não me refiro ao comportamento, mas às questões do sujeito. De uma parte, temos a ação de uma droga de efeitos rápidos que pode provocar dependência em curto tempo. De outra parte, aí encontramos uma espécie de clã urbano, fruto de extrema miséria social, cujos membros são comandados pelo consumo de uma substância que identifica os usuários.

Não se trata da identificação aos atributos significantes do pai ou de seus substitutos, mas do domínio de uma droga que decide pelo sujeito. Antes de tudo, essas identificações "repousam no reconhecimento da posse de uma substância comum e podem mesmo ser criadas por uma refeição ingerida em comum" (FREUD, 1921: 139). No caso do crack, a refeição é substituída pela fumaça da "pedra", pois os usuários dão pouca importância à alimentação, desde que esta droga inibe o apetite. Trata-se de um ritual que comemora o desconhecimento do vazio, em oposição ao ritual totêmico que ao comemorar o vazio produzido pela morte do pai produz os laços simbólicos que fundam as leis e regras da convivência social.

\footnotetext{
${ }^{6} \mathrm{O}$ totemismo é um sistema que regulamenta as relações sociais e religiosas de grupos cujos membros tomam um animal, planta ou fenômeno da natureza como seu ascendente (FREUD, 1913).
} 
Sem perder de vista que uma multidão de seres humanos dificilmente pode reunir-se sem possuir os rudimentos de uma organização, Freud (1921) sublinha a função identificatória exercida pelo interesse no mesmo objeto. A identificação daí resultante permite que uma multidão ocasional componha um grupo, no sentido psicológico. Mesmo os "grupos de caráter efêmero, que algum interesse passageiro apressadamente aglomerou a partir de diversos tipos de indivíduos" (FREUD, 1921: 108). São os "grupos simples", caracterizados pelo apagamento das dessemelhanças entre membros, em prol das funções inconscientes, comuns a todos, o que determina a redução da censura e, consequentemente, do controle. Como a afetividade predomina sobre o funcionamento intelectual, existe uma tendência para transformar ideias em atos, sem reflexão.

E, finalmente, os grupos nunca ansiaram pela verdade. Exigem ilusões e não podem passar sem elas. Constantemente dão ao que é irreal precedência sobre o real; são quase tão intensamente influenciados pelo que é falso quanto pelo que é verdadeiro. Possuem tendência evidente a não distinguir entre as duas coisas (FREUD, 1921: 104).

Essas considerações sobre a psicologia dos grupos podem ser lidas, sem exceção, como relativas aos meninos em situação de rua, no Pelourinho. Em torno de um objeto comum, o crack, os usuários identificam-se. A procura de gozo assinala o predomínio das funções inconscientes e a dependência ao objeto acentua a tendência para passar ao ato. Além disso, o consumo de drogas intensifica as produções imaginárias, em detrimento do simbólico. A satisfação é então obtida não com representações, mas a partir da presentificação do objeto, enquanto as identificações configuramse a partir "de comunidades reunidas em torno de um mesmo gozo" (MELMAN, 2003: 126). Identificações coletivas construídas de modo frágil e que não favorecem o encontro com a singularidade de cada sujeito.

Mas, além da droga, quais os outros traços que orientam a identificação desses sujeitos? Antes de prosseguir, gostaria de lembrar que as referências tradicionais que asseguravam identidades estáveis, baseadas na identificação ao pai, estão sendo deslocadas em prol de uma constante reavaliação das práticas sociais. Como resultado de mudanças estruturais e institucionais, o sujeito contemporâneo é obrigado a inventar-se, o que o leva a assumir "várias identidades em diferentes momentos, identidades que não são unificadas ao redor de um 'eu' coerente" (HALL, 2006: 13). Isto se traduz na perda do sentido unívoco de si mesmo e na busca de novos referenciais. 
E quais são as referências para crianças e adolescentes em situação de rua? Eles não contam com o apoio da família, nem dispõem de escolas, abrigos, centros de saúde e lazer adaptados às suas singularidades. Tampouco têm acesso aos objetos de consumo que funcionam como insígnias de inscrição social, o que favorece o envolvimento em situações de risco, como roubos, assaltos e exploração sexual. Paralelamente, se a indústria cultural define de forma unilateral, estereotipada e condenatória os diferentes traços que devem ser assumidos por grupos distintos, eles estão "fora de moda", pois se vestem com farrapos, andam sujos e descalços e alimentam-se com restos de comida. De fato, eles contam com poucas referências identificatórias; e com base no trabalho de campo desenvolvido no Centro Histórico de Salvador, circunscrevo, além da droga, quatro categorias para efeito de análise, ou seja, espaço, tempo, relação com a polícia e "língua do pivete".

No geral, o espaço e o tempo delimitam uma estrutura simbólica para que cada sujeito apreenda sua posição social. São valores determinados culturalmente que incidem sobre as representações do sujeito e definem suas relações na sociedade. Parte-se do princípio, estabelecido pelo senso comum, que há um tempo e um lugar para cada prática social. Segundo Hall (2006: 72), o lugar deve ser entendido como ponto "específico, concreto, conhecido, familiar, delimitado: o ponto de práticas sociais específicas que nos moldaram e nos formaram e com as quais nossas identidades estão estreitamente ligadas". De sua parte, Michel Maffesoli situa o espaço como um elemento de mediação entre a natureza e a cultura, condição básica para a existência humana; enquanto o lugar comporta representações socioculturais que incidem sobre a construção das identificações do sujeito.

Trata-se de lugares em que é possível o indivíduo se reconhecer enquanto se identifica com os outros, lugares em que, sem nos preocuparmos com o controle do futuro, administramos nosso presente, lugares, enfim, onde se elabora a forma de liberdade intersticial que está em contato direto com o que é próximo e concreto. Tudo isso faz do espaço-vivenciado não o refúgio de um individualismo amedrontado e imóvel, mas a base a partir da qual se efetuam as incursões, as 'investidas' que, pouco a pouco, vão constituindo a órbita de uma nova socialidade (MAFFESOLI, 2004: 66).

Existe uma concordância conceitual entre esses autores, embora a originalidade de Maffesoli consista na articulação do lugar como elemento gerador de elos. Assim constitui-se uma forma de liame social, característico da pós-modernidade, que estrutura tribos urbanas de maneira efêmera, a 
partir de interesses diversificados e em busca dos tradicionais anseios de solidariedade e proteção.

Em conversa informal com a antropóloga Goli Guerreiro ${ }^{7}$, avaliamos conjuntamente a pertinência de aplicar o conceito de tribos urbanas aos meninos em situação de rua. Dada a complexidade do tema restaram dúvidas, embora tenha se mostrado um empreendimento frutífero recorrer aos fundamentos epistemológicos utilizados por Maffesoli para dialogar com o objeto deste estudo. Entre esses, destaco o predomínio da imagem na constituição subjetiva, um uso específico de linguagem e a ênfase no presente "que contamina as representações e as práticas sociais, em particular as juvenis. [...] O gozo não é mais remetido a hipotéticos e 'róseos amanhãs', não mais é esperado num paraíso futuro, e sim vivido, seja lá como for, no presente" (MAFFESOLI, 2004: 27-28).

Os pontos de vista de Maffesoli encontram correspondência no conceito freudiano de identificação. Pois se trata de manifestações estéticas que agregam aqueles que pensam e sentem de modo similar, de movimentos éticos que organizam o laço social com base na empatia, bem como de costumes que fundamentam o estar junto. A partir do mecanismo de identificação, organiza-se a dinâmica da rua que comporta a presença de novos integrantes e a ausência de outros que, por motivos diversos, migram para diferentes lugares. No que diz respeito à circulação, é fato que os meninos em situação de rua movimentam-se constantemente e reúnem-se de forma fluida e efêmera, o que é compatível com a conceituação de tribos urbanas.

Contudo, não podemos esquecer que existe uma tendência para fixarse em lugares que oferecem condições de segurança e satisfação. Como no Pelourinho, onde o elo é formado, antes de tudo, a partir do interesse pelo crack que funciona como referente para a identificação de meninos que aí permanecem há mais de quatro anos. A fixação no lugar contrapõe-se, portanto, à mobilidade observada entre as tribos urbanas. Desse ponto de vista, a denominação de clã urbano me parece mais apropriada. No entanto, aqui importa menos a classificação terminológica do que a qualidade das identificações construídas nas ruas do Centro Histórico de Salvador.

O afastamento de casa, lugar essencial para a construção identitária, repercute sobre as representações do sujeito que dispõe apenas do espaço da rua. Neste ponto, é interessante observar que apenas Jack afirmou que

\footnotetext{
${ }^{7}$ Goli Guerreiro tomou o tema das tribos urbanas como objeto de Dissertação.
} 
não tinha condição de voltar para casa por conta dos conflitos familiares que colocavam sua vida em risco. Os demais relataram que possuíam uma família relativamente estável, mas que preferiam a rua, "por causa do vício da droga". Não podemos esquecer, no entanto, que os "meninos de rua" também fogem da violência doméstica, do maltrato e omissão por parte dos pais, de casas tristes e pobres, onde não há lugar para todos. Além disso, no geral, "a rua é mais segura que suas casas" (SILVA, 1996: 40).

Independente dos riscos experimentados, eles encontram na rua a liberdade para fazer quase tudo que querem, sem sofrer violência nem repressão dos pais, sem compromisso com qualquer tipo de horário ou atividade. Para essas crianças e adolescentes, "[em] algum nível, por mais oprimidos e miseráveis e pressionados pelas circunstâncias, há uma ênfase em algum tipo de liberdade. Um ato de escolha" (VELHO, 1996: 249). O problema é que a "escolha" se apresenta de forma bastante limitada, pois de fato apenas duas alternativas parecem possíveis, ou seja, ou a desestruturação familiar ou a rua, pois não existe instituição de retaguarda capaz de atender essas crianças com eficiência. Entretanto, será que podemos falar, de maneira generalizada, de uma demanda para sair da rua? Em caso afirmativo, quantas crianças e adolescentes estão, de fato, dispostos a abandonar a liberdade conquistada nas ruas?

Em um estudo sobre população análoga, Hélio Silva coloca questões a respeito do valor conferido por meninos em situação de rua àquilo que usualmente lhes é oferecido como alternativa para sair da rua. $\mathrm{O}$ autor lembra que o conjunto de hábitos e estilo de vida, assim adquiridos, configura "uma classe popular com vícios aristocráticos, carpe diem" (SILVA, 1996: 29). Esta afirmação pode provocar certa inquietação, na medida em que reconhecemos as condições degradantes que conformam a vida desses meninos, em oposição aos luxos aristocráticos. Entretanto, não podemos esquecer que de modo análogo à aristocracia, eles também estão alijados da produção capitalista e dos valores burgueses que lhes são inacessíveis. A este respeito, as contribuições deste autor oferecem subsídios para que possamos refletir sobre os comportamentos de risco assumidos por esses jovens:

Desvalorizam - luxo aristocrático - a própria vida, o futuro e todas as promessas do mundo por um gesto gratuito pelo qual podem pagar o preço maior. $\mathrm{Ou}-$ realistas inveterados - sabem de antemão que não há nenhuma promessa e que os fracassos reiterados de toda sua ascendência, vizinhança, parentela e redes de amigos já provaram que o tempo não existe (SILVA, 1996: 30). 
A ausência de preocupações com o futuro e mesmo com a própria vida aparece como solução para enfrentar a falta de expectativas e crenças nas promessas de terceiros. Nos casos aqui analisados, o gozo do crack associa-se com o gozo proporcionado pela liberdade usufruída graças ao afastamento de casa. O preço é alto, pois de maneira precoce esses indivíduos passam a conviver com inúmeros riscos, quase sempre sem ter quem os proteja. Apesar da miséria biopsicossocial, a experiência da liberdade diminui a repressão e, por isso mesmo, produz uma quota a mais de gozo. Podemos então concluir que independente das razões que haviam motivado a saída de casa, a possibilidade de comprar e consumir crack sobrepõe-se como índice para definir o movimento e a permanência no Centro Histórico de Salvador.

Entre os hábitos que fundamentam o estar junto, gostaria de citar a utilização do pátio externo da Igreja de São Pedro dos Clérigos, no Pelourinho, como dormitório, onde os meninos se amontoam em busca de proteção, após uma noite de consumo intenso de crack. Assim que despertam, costumam pedir dinheiro e comida nas portas das lanchonetes, onde não podem entrar, pois são acusados de aí protagonizarem conflitos e impasses. Para alguns, as Fontes do Terreiro de Jesus e da Praça da Sé são utilizadas para um banho improvisado, após burlarem a vigilância dos policiais que se esforçam para mantê-los afastados.

$\mathrm{Na}$ ânsia de obter dinheiro, eles procuram ocupar pontos estratégicos à procura de turistas que costumam lhes dar dinheiro, quase sempre gasto na compra de crack. Os estrangeiros, sobretudo, atraem sua atenção, pois os meninos sabem que podem ganhar quantias significativas que, por vezes, atingem a cifra de cem reais. Para facilitar a comunicação, alguns chegam a aprender palavras e expressões em inglês, como hello, good morning, give me money. Outro costume corriqueiro consiste na troca de alimentos por pedras de crack, graças à conivência dos traficantes. Contudo, se alguém "some" quase sempre é possível informar-se sobre seu paradeiro com os que estão presentes. Este breve relato permite concluir que apesar da aparente dispersão há um mínimo de coesão, participação coletiva em práticas e atividades exercidas em comum por este clã urbano.

No que diz respeitoà imagem como elemento norteador de identificações, é fato que as precárias condições da vida na rua interferem na aparência e nos cuidados com o corpo. O fato de estarem quase sempre maltrapilhos, sujos, descalços e vestidos com roupas inadequadas não deixa de ter repercussões negativas sobre as representações do sujeito. Neste ponto, gostaria de 
lembrar que para Foucault (1977), o corpo representa o elemento irredutível do esquema social onde se exercem as forças de repressão, socialização, disciplina e punição. Os meninos em situação de rua, no entanto, escapam às técnicas de controle, na contramão do que é proposto pelas sociedades disciplinares que ditam de modo imperativo como cuidar do corpo. Mais uma vez, prevalece a ética do instante e o imperativo de gozo que determina a degradação biopsicossocial dos usuários de crack.

No Pelourinho, a relação com o tempo estrutura práticas sociais que asseguram sentimentos de pertencimento ao grupo e incidem sobre a autoestima. A passagem do tempo é marcada pela alternância entre a mendicância, a compra e o consumo de drogas, a negociação para conseguir um lanche e a procura de um lugar seguro para dormir. Assim o tempo contrai-se no espaço, guiado por dois fatores que operam na necessidade contemporânea de dar forma ao tempo. Trata-se da acentuação do presente que visa o gozo, no aqui e agora, e da preponderância da imagem na organização social. Desse modo, configura-se "o 'espírito do lugar', isto é, aquilo que faz com que o tempo ganhe forma" (MAFFESOLI, 2004: 52). Neste sentido, o "espírito do Pelourinho" configura, atualmente, uma grave questão social caracterizada pelo tráfico e uso de drogas por um número crescente de crianças e adolescentes em situação de rua.

Embora a vontade de esquecer os sofrimentos passados não deixe de produzir repercussões sobre as representações do sujeito, as recordações estruturam campos que servem como referências para a construção identitária. Destaco aqui as lembranças sobre o relacionamento com os policiais que na qualidade de representantes da lei interferem nas identificações do sujeito, como cidadão ou marginal, o que pode ser conferido neste fragmento:

Jack: - Na rua, dormindo na rua. Em tempo dos outro pegá meter a pedra na cabeça, pisar na cabeça, hein? Tocar fogo, a gente dormindo na igreja ali. Os policiamento pega a gente pra bater de pancada. Fala aí, hein. Os menino maior pega a gente pra fazer perversidade. Né não, é?

Mário: - É isso mesmo. Um policial hoje meteu foi cacetada ni minha perna.

Leila: - Hoje?

Mário: - Ontem.

Jack: - Ontem de noite.

Leila: - Por que, Mário?

Mário: - Eu tava passando aí no Terreiro, ele meteu cacete! Disse: - Num quero mais ver você aqui. 
Os sentimentos de exclusão surgem associados com falhas na memória a respeito de um acontecimento que por ser corriqueiro interfere na relação com o tempo. Assim, Mário não sabe ao certo quando apanhou da polícia. Esta aparece como um inimigo que reprime não apenas os atos ilícitos; como também limita a presença dos corpos no lugar. No Pelourinho, os "meninos de rua" são impedidos de permanecer em determinados locais, bem como de ter acesso a estabelecimentos como lojas e lanchonetes, mesmo quando têm dinheiro para pagar. Desse modo, constituem-se laços sociais de valor negativo, pois o ódio contra a polícia estrutura identidades, pautadas na exclusão social, desde que as normas são impostas através da força física, em detrimento da palavra. Frente à violência, os meninos em situação de rua utilizam uma estratégia linguageira conhecida como "língua do pivete".

\section{4. “LÍNGUA DO PIVETE”}

A "língua do pivete" consiste na inversão de sílabas, no intuito de criar uma versão distorcida das palavras, o que possibilita a comunicação na presença de terceiros, compreendida apenas pelos "enturmados". Por isso, ela é corriqueiramente empregada para a troca de informações sobre temas proibidos, como aquisição e consumo de drogas, organização de roubos e furtos. Com esta estratégia, os "meninos de rua" podem falar do outro ou mesmo ofendê-lo, sem que este entenda. "Viadovi", por exemplo, utilizado habitualmente como xingamento, significa "viado". Trata-se de uma construção aparentemente simples, embora o ritmo acelerado da fala impeça a compreensão dos não iniciados. Entretanto, de tanto escutar, consegui aprender ao menos uma frase: "Cevô, noá besá alafá a lingualin do vetipi" ou "Você não sabe falar a língua do pivete".

Embora se trate de uma forma peculiar de comunicação, não consegui identificar estudos específicos sobre o tema. Portanto, existem aspectos da vida desses meninos, linguísticos e culturais, que ainda não foram devidamente pesquisados. Com isso, delineiam-se questões, inclusive de ordem política, que apontam para a importância de circunscrever o conhecimento que atualmente dispomos sobre esses sujeitos que, em parte, fundamenta os programas que lhes têm sido propostos. Na ausência de referências bibliográficas, vou tecer algumas considerações baseada na teorização sobre o uso de gírias; e do verlan francês, cuja lógica de construção assemelha-se à que pude observar na "língua do pivete". 
De maneira geral, o uso de uma forma específica de comunicação assinala a "necessidade de criação de códigos que, como escudos, esconderijos, máscaras, produzem uma linguagem apenas compreendida entre os enturmados" (DIÓGENES, 2000: 207). O modo cifrado de comunicação demarca a tentativa de sublinhar a diferença e, consequentemente, a identificação a determinado grupo. Trata-se de um recurso particularmente efetivo para as vítimas de exclusão social que, desse modo, podem enunciar o que não pode ser dito em determinadas circunstâncias.

Em conversa informal com o professor Michel Colin ${ }^{8}$, tomei conhecimento do verlan, uma linguagem informal, falada, sobretudo, nos subúrbios ou banlieues dos grandes centros urbanos franceses. O termo é formado pela inversão da palavra francesa lenvers, que significa "avesso", e seu aparecimento está associado com a necessidade de obscurecer o significado das palavras, por aqueles que precisam comunicar-se na presença de terceiros sem serem compreendidos. De maneira similar à "língua do pivete", não existe forma escrita e a pronúncia decide pelo emprego das palavras, construídas basicamente a partir da inversão silábica, de modo que as sílabas iniciais passam a ocupar o final da palavra e vice-versa. A sonoridade decide pelo acréscimo de vogais, de modo a formar uma nova sílaba; ou pelo apagamento da última sílaba.

Considerado um fenômeno de origem parisiense, até a década de 70, apenas marginais e moradores de rua empregavam o verlan. Entretanto, sua utilização como recurso estético contemporâneo, por escritores, cineastas, compositores e rappers, resultou em sua popularização entre adolescentes e jovens suburbanos. A partir dos anos 90, esta linguagem codificada espalhou-se entre a população francesa, dos subúrbios para as áreas no centro de Paris, ocupadas pela classe média. Alguns adultos passaram a empregá-la no intuito de demonstrar conhecimento ou afinidade com a geração jovem, enquanto algumas palavras foram incorporadas à linguagem cotidiana, ao ponto de serem utilizadas sem que se tenha conhecimento da sua origem. Certas frases são caracterizadas pelo aparecimento pontual de uma ou mais palavras em verlan que, atualmente, serve não apenas para abordar temas tabus, mas também como veículo identitário que expressa interesses comuns, estilo e condições de vida similares.

\footnotetext{
${ }^{8}$ Michel Colin nasceu em Pont-Croix, na França. Licenciado em Língua Portuguesa, atualmente leciona na Aliança Francesa, em Salvador-BA.
} 
É fato que o uso de uma língua costuma variar em função de aspectos temporais e socioculturais. Com relação às gírias e linguagens alternativas, as especificidades dependem das características dos grupos, das circunstâncias e da identidade daquele que fala; o que inclui idade, sexo e posição social, entre outros fatores. Para os meninos em situação de rua, a "língua do pivete" funciona como uma estratégia de sobrevivência que configura a chance de burlar a lei, enfrentar perigos e agressões, além de funcionar como um recurso lúdico em situações de lazer, o que favorece a identificação ao grupo. Para Jack, 16 anos, em situação de rua, no Pelourinho, trata-se de "uma língua bem fácil pra falar. [...] Pra polícia não entender o que a gente tá falando. Se quiser fugir da polícia, a gente fala na língua do pivete".

Desse modo, crianças e adolescentes em situação de rua utilizam a língua como um recurso identitário, uma estratégia lúdica que acaba por se revelar crucial para a sobrevivência do grupo ao facilitar o enfrentamento de situações de risco e violência. Com a "língua do pivete", eles constroem muralhas de proteção e fortalecem os laços do grupo, pois assim preservam a comunicação em situações nas quais não querem ser compreendidos, particularmente as de confronto com a lei. Paradoxalmente, com isso acentuam sua posição marginal, na mesma direção dostraçosidentificatórios até aqui delimitados, ou seja, droga, lugar, tempo e relação com a polícia.

\section{CONCLUSÃO}

Pelo que até aqui vimos, o rap pode ser utilizado como um recurso narrativo para constituir o laço social, abordar as questões do sujeito e favorecer a troca de informações sobre fatores de risco e proteção. Tratase de um suporte identificatório que oferece alternativas para a formação de identidades construídas segundo a lógica da exclusão social. A análise das diferentes textualidades aqui apresentadas permite o delineamento de características comuns ao grupo - tal como a qualidade do laço com o rap - a partir das quais podemos encontrar subsídios para o desenvolvimento de uma práxis cultural orientada por objetivos psicossociais.

De fato, o rap veicula elementos significantes que cumprem as exigências de qualidade comum partilhada com as histórias de vida dos meninos em situação de rua. Também não podemos esquecer que, independente do estilo musical, alguns cantores são considerados ídolos, tomados como modelos paradigmáticos, sobretudo para adolescentes e jovens. Especificamente no que diz respeito aos rappers, a resistência e as reivindicações sociais que 
atravessam o movimento hip-hop representam condições que favorecem sua eleição como figuras ideais para os meninos em situação de rua. Assim, é possível ser alguém, como os rappers, que representam uma possibilidade de inserção social e mesmo comercial para as comunidades periféricas, sem abrir mão dos traços que caracterizam os grupos marginalizados.

Diante do empobrecimento simbólico provocado pela droga, o rap constitui um recurso para falar de si e mesmo para refletir sobre as próprias posições, frente a temas que estão estreitamente relacionados com as questões do sujeito. A natureza simbólica deste tipo de identificação contrapõe-se àquela proporcionada pelo consumo de drogas, que imprime um tipo de memória no corpo não mediada pela palavra.

Em contrapartida, os resultados obtidos com as Oficinas de contos realizadas na rua demonstram que o tempo também pode ser empregado para aí constituir um espaço de palavra e subjetivação. As lembranças partilhadas sobre o passado recente demonstram a existência de laços sedimentados em vivências experimentadas coletivamente. Neste ponto, convém lembrar que a memória coletiva representa um fator de identificação e coesão para os membros de um grupo. Para os participantes deste estudo, as narrativas cantadas ofereceram a possibilidade de transmissão e reflexão sobre fatores de risco - como uso de drogas, participação em roubos e posição numa família desestruturada - bem como sobre estratégias de redução de danos.

Mesmo que isto tenha ocorrido graças à apropriação do discurso dos cantores, o rap permitiu inscrever alguma descontinuidade no registro mudo da identificação à droga. Sob o viés da droga, a tentativa de subjetivação fracassa, na medida em que o sujeito só pode ser representado pelo significante. Enquanto a qualidade simbólica da identificação ao rap favorece a construção do laço social, permite o acesso ao lazer, estimula a procura de informações, como também permite dar voz às questões subjetivas.

Assim, delimita-se uma forma de utilizar a cultura urbana contemporânea - que afeta meninos em situação de rua - para enfrentar o empobrecimento simbólico e a dificuldade para falar, provocados pela miséria, violência e uso de substâncias psicoativas. Não se trata de um processo simples e faço esta afirmação com base nos desdobramentos observados nas Oficinas de contos. Um dos principais riscos consiste na qualidade da identidade promovida por intermédio da transmutação de elementos estigmatizados, como no caso do rap.

Por vezes, os limites entre a diversão e a transgressão podem ser 
facilmente diluídos, sobretudo quando os adolescentes apresentam interesse pelo "gangsta rap". Este interesse pode determinar a sedimentação de traços perversos, entre os quais se destacam os que estão relacionados com a legitimação de atividades ilícitas. Daí a importância da constituição de um espaço de palavra, logo após o canto. Desse modo, os participantes têm oportunidade para associar livremente, no intuito de pôr em cheque ideias e posições relacionadas com a temática dos raps escolhidos. Este procedimento foi levado a termo com o auxílio da contação de histórias, o que indica que as narrativas ritmadas podem ser empregadas como um recurso alternativo, em oficinas especialmente planejadas para esses jovens.

Os autores consultados consideram que o rap representa uma resposta para a exclusão social, no sentido da construção de cidadania. O engajamento como cantor tem levado alguns rappers a declarar que retomaram os estudos na tentativa de buscar conhecimentos para escrever as letras de suas canções. Outros confirmam o papel do rap como alternativa para enfrentar as dificuldades com o mercado de trabalho, envolvimento com o tráfico e o consumo de drogas. Paralelamente, os centros de atenção psicossocial para tratamento de usuários de álcool e outras drogas costumam incluir oficinas de rap no plano terapêutico de seus pacientes.

A identificação com este estilo musical revela as semelhanças significantes entre as letras das canções e as histórias de vida desses meninos. Assim é possível abalar a identificação à droga, na medida em que o "processo de identificação, através do qual nos projetamos em nossas identidades culturais, tornou-se mais provisório, variável e problemático" (HALL, 2006: 12).

Já não se trata de assumir esta ou aquela identidade, mas da fluidez de identificações que, por vezes, assumem caráter contraditório. Cada vez mais, "somos confrontados por uma multiplicidade desconcertante e cambiante de identidades possíveis, com cada uma das quais poderíamos nos identificar - ao menos temporariamente" (HALL, 2006: 13). E desde que o processo de identificação opera de forma contínua, a estrutura da identidade permanece aberta, o que legitima a tentativa de abalar a identificação à droga com o auxílio do rap. Este tipo de identificação opera de forma fluida, em função de sua natureza simbólica, sem necessariamente promover a "colagem" entre o sujeito e o objeto, tal como ocorre com a droga. O processo é facilitado pelo modo através do qual o sujeito é interpelado ou representado pelo Outro, o que deve ser tomado como princípio ético para o planejamento e realização de oficinas de contos e raps com objetivos de prevenir, tratar e reduzir os riscos e danos relacionados com o consumo de 
substâncias psicoativas.

Independente do estilo musical, a função identificatória da música já havia sido apontada por Jorge Amado, no romance Capitães da areia, que de maneira aguda e sensível indica como a música gerava sentimentos de fraternidade entre os meninos que viviam nas ruas de Salvador, no início do século XX: "E amaram-se uns aos outros, se sentiram irmãos porque eram todos eles sem carinho e sem conforto e agora tinham o carinho e conforto da música" (AMADO, 1996: 59). 


\section{REFERÊNCIAS BIBLIOGRÁFICAS}

ABRAMOVAY, Miriam et. al. Gangues, galeras, chegados e rappers: juventude, violência e cidadania nas cidades da periferia de Brasília. Rio de Janeiro: Garamond, 1999.

AMADO, Jorge. Capitães da areia. Ilustrações de Poty. 85. ed. Rio de Janeiro: Record, 1996.

ARCE, José M. Valenzuela. O funk carioca. In: HERSCHMANN, Micael (Org.). Abalando os anos 90: funk e hip-hop: globalização, violência e estilo cultural. Rio de Janeiro: Rocco, 1997. p. 136-163.

CARVALHO, Maria Alice Rezende. Violência no Rio de Janeiro: uma reflexão política. In: PEREIRA, Carlos Alberto Messeder et. al. (Org.). Linguagens da violência. Rio de Janeiro: Rocco, 2000. p. 47-74.

CHANG, Jeff. Can't Stop, Won't Stop: a History of the Hip-Hop Generation. Great Britain: Cox \& Wyman Ltd, Reading, Berkshire, 2007.

CRUGLAK, Clara. Clínica da identificação. Rio de Janeiro: Companhia de Freud, 2001.

DIÓGENES, Glória. Gangues e polícia: campos de enfrentamento e estratégias de diferenciação. In: PEREIRA, Carlos Alberto Messeder et al. (Org.). Linguagens da violência. Rio de Janeiro: Rocco, 2000. p. $197-220$.

FAUSTO NETO, Ana Maria Q.; QUIROGA, Consuelo. Juventude urbana pobre: manifestações públicas e leituras sociais. In: PEREIRA, Carlos Alberto Messeder et al. (Org.). Linguagens da violência. Rio de Janeiro: Rocco, 2000. p. 221-235.

FOUCAULT, Michel. História da sexualidade: a vontade de saber. Trad. Maria Thereza da Costa Albuquerque e J. A. Guilhon de Albuquerque. Rio de Janeiro: Edições Graal Ltda, 1977. v. 1.

FREUD, Sigmund. Escritores criativos e devaneio (1908). In: FREUD, Sigmund. 'Gradiva' de Jensen e outros trabalhos. Rio de Janeiro: Imago, 1976. p. 145-158. (Edição Standard Brasileira das Obras Psicológicas Completas de Sigmund Freud, 9). 
FREUD, Sigmund. Psicologia de grupo e a análise do ego (1921). Rio de Janeiro: Imago, 1976. (Edição Standard Brasileira das Obras Psicológicas Completas de Sigmund Freud, 18).

FREUD, Sigmund. Totem e tabu (1913). In: FREUD, Sigmund. Totem e tabu e outros trabalhos. Rio de Janeiro: Imago, 1976. p. 20-191. (Edição Standard Brasileira das Obras Psicológicas Completas de Sigmund Freud, 13)

HALL, Stuart. A identidade cultural na pós-modernidade. Trad. Tomaz Tadeu da Silva e Guacira Lopes Louro. 11. ed. Rio de Janeiro: DP\&A, 2006.

HERSCHMANN, Micael. Na trilha do Brasil contemporâneo. In: HERSCHMANN, Micael (Org.). Abalando os anos 90: funk e hip-hop: globalização, violência e estilo cultural. Rio de Janeiro: Rocco, 1997. p. $52-83$.

LACAN, Jacques. O seminário, livro 5: as formações do inconsciente. Trad. Vera Ribeiro. Rio de Janeiro: Jorge Zahar Editor, 1999.

MAFFESOLI, Michel. Notas sobre a pós-modernidade: o lugar faz o elo. Rio de Janeiro: Atlântica Editora, 2004.

MELMAN, Charles. O homem sem gravidade: gozar a qualquer preço. Entrevistas por Jean-Pierre Lebrun. Trad. Sandra Regina Felgueiras. Rio de Janeiro: Companhia de Freud, 2003.

ROSE, Trícia. Um estilo que ninguém segura: política, estilo e a cidade pós-industrial no hip-hop. In: HERSCHMANN, Michael (Org.). Abalando os anos 90: funk e hip-hop: globalização, violência e estilo cultural. Rio de Janeiro: Rocco, 1997. p. 190-213.

SANSONE, Lívio. Funk baiano: uma versão local de um fenômeno global? In: HERSCHMANN, Micael (Org.). Abalando os anos 90: funk e hip-hop: globalização, violência e estilo cultural. Rio de Janeiro: Rocco, 1997. p. 166-187. 
SILVA, Hélio R. S. O menino, o medo e o professor de Saarbrucken. In: VELHO, Gilberto; ALVITO, Marcos (Org.). Cidadania e violência. Rio de Janeiro: Editora UFRJ; Editora FGV, 1996. p. 26-48.

VELHO, Gilberto. O menor e a violência. In: VELHO, Gilberto; ALVITO, Marcos (Org.). Cidadania e violência. Rio de Janeiro: Editora UFRJ; Editora FGV, 1996. p. 247-265. 